\title{
THE ARCHEOLOGIST'S STICK
}

The archeologist's stick is a great help, and it varies with the work and locality. It may be a few inches long to shoulder high. You pick up anything handy for small jobs-a piece of lath, a broken bit of branch or a stout length of wire or rod. Anything will do that will save your back from bending and your finger nails from digging. You use it to scratch, and poke, and turn over the interesting objects you see in your search for artifaats.

A short stick is best for very small artifacts, so you can bend over close to the job, and scratch and poke in the mud and gravel. A short stick is also useful in a site that has been well picked over and the large and easily found articles removed. That means that only small and well hidden articles are left, and you must scratch and get down close to see them.

A long and strong stick is best for rough and rocky ground, down-timber, and drift-wood on a beach. Cut a stout on that reaches to your shoulder and put a spike in the end. A spike may be made by sawing the head off a big nail and driving it into the end of your stick with the sharp end outward. This spike is handy for testing leaves and bark that look like artifacts, and with it you can tell by the sound whether an article is stone or pottery. Remember, you bend down and pick up many, many times a day; and anything that will save you benddowns and pick-ups is a friend indeed.

Your long stick is handy for sounding boggy spots. It is useful when climbing down or wind-fall timber or driftwood, and the end spike keeps it from slipping off loose bark, slimy logs, or roots.

The strong staff with its spike helps you up and down when climbing rock outcrop or broken rock. You can use it as a third leg to test a loose rock for roll and slip, before taking the weight off your other foot. Along the Pinawa Channel in Manitoba the huge pieces of blasted rock to be climbed over are piled up thirty or forty feet high, with no soil whatever; and in places like that you will find a strong spiked staff very useful.

You can poke your long staff into the mud and use it for a boat anchor when nothing else offers. Stood up, it can be used as a marker or reference point. It is useful to knock water off drenched weeds and brush, and very handy in parting weeds and grass that grow up around artifacts. It is also handy to hang a pot over the camp fire, and, when tired, you can use it for a staff to lean on, or help you on your way.

Green birch makes a good staff and it dries out quickly when peeled. It is then light, strong, and so "Good to the feel" that you hope and pray it will find for you at least one artifact per hour. Choose the thickness by your weight, but be sure it is strong enough to take all your weight without breaking. There are times and places where a broken staff might cause a bad fall and serious injury. It might also let you down when climbing rock faces over deep, swift and dangerous water. The long staffs of the old-time shepherds who scrambled over the rocks of Palestine were not carried for ornament.

\section{BEAUTY IS ALWAYS PRESENT}

(Continued from Page 8)

mals. Squirrels are uncommon on our spruce-shy farm.

I crossed a rabbit run tunneling through a dense patch of sun-cured peavine and bristling rose bushes. A coyote had passed that way too. His tracks showed plainly in a strip of shallow snow.

I halted for a moment by a flat slab of granite. A few shreds of a scarlet rose hip were scattered on the rock's grey surface. A mouse, no doubt, had dined at this, "table in the wilderness".

Nearing home, I discovered a few white heads of spicy yarrow, and a number of short-stemmed dandelions upon a sheltered sidehill. How beautiful these unexpected flowers seemed. A November bouquet, a token to remind us that beauty is always present if we but stop to see it. 